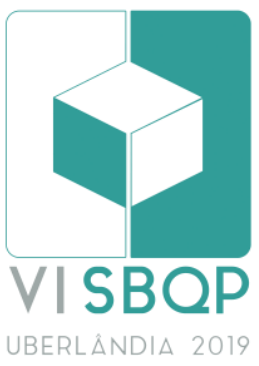

\title{
CERTIFICAÇÃO AMBIENTAL DE EDIFICAÇÕES PARA USO RESIDENCIAL: ANÁLISE CRÍTICA
}

\author{
SARAMAGO, Rita de Cássia Pereira \\ Universidade Federal de Uberlândia, e-mail: saramagorita@gmail.com \\ LOPES, João Marcos Almeida de \\ Instituto de Arquitetura e Urbanismo da Universidade de São Paulo, e-mail: \\ jmalopes@sc.usp.br
}

\begin{abstract}
RESUMO
Este trabalho apresenta resultados parciais da pesquisa de doutorado em desenvolvimento, que investiga o conceito de sustentabilidade e sua aplicação na Arquitetura. Considerando o crescente número de empreendimentos que anunciam o emprego de estratégias de sustentabilidade, a pesquisa também objetiva questionar os resultados dessa produção. Para tanto, propõe-se a analisar os principais métodos de certificação ambiental de edificações que têm sido aplicados no Brasil: LEED, AQUA e Casa Azul - tidos como legitimadores do que se entende por arquitetura sustentável. A presente comunicação analisa as metodologias voltadas ao uso residencial, por meio da elaboração de quadros comparativos sobre as categorias e os critérios de cada processo. Verificou-se que, quando comparados entre si, todos os métodos são incompletos, apresentando lacunas que podem comprometer a aferição do real desempenho ambiental das edificações certificadas.
\end{abstract}

Palavras-chave: Sustentabilidade, Certificação de edificações, LEED, AQUA, Casa Azul.

\begin{abstract}
This paper presents partial results of the PhD research in development, which investigates the concept of sustainability and its application in Architecture. Considering the increasing of buildings that announce the use of sustainability strategies, the research also aims to question this production. Therefore, it proposes to analyze methods of environmental certification of buildings applied in Brazil: LEED, AQUA and Casa AzUl - perceived as legitimating sustainable architecture. This paper presents the analysis of methodologies for residential use, through the elaboration of comparative tables on the categories and criteria of each process. It was verified that, when compared to each other, all methods are incomplete, presenting gaps that may compromise the real environmental performance of certified buildings.
\end{abstract}

Keywords: Sustainability, Building Certification, LEED, AQUA, Casa AzUl.

\section{INTRODUÇÃO}

O conceito de sustentabilidade, desde sua difusão no final dos anos 1980, vem sendo aplicado para justificar práticas bastante diferenciadas. Visando distingui-las, empresas de variados ramos têm buscado conquistar selos de certificação ambiental para seus processos e produtos. No caso específico dos empreendimentos imobiliários, Vasconcelos e Vasconcelos (2008) afirmam que a preocupação com a sustentabilidade também tem ganhado visibilidade a partir da participação de empresas do setor em processos de certificação responsáveis por classificarem as edificações quanto ao nível de desempenho ambiental obtido, segundo indicadores diversos.

SARAMAGO, R. C. P.; LOPES, J. M. A. Certificação ambiental de edificações para uso residencial: análise crítica. In: SIMPÓSIO BRASILEIRO DE QUALIDADE DO PROJETO NO AMBIENTE CONSTRUÍDO, 6., 2019, Uberlândia. Anais... Uberlândia: PPGAU/FAUeD/UFU, 2019. p. 397-410. DOI https://doi.org/10.14393/sbqp19038. 
Ao longo do tempo, diferentes selos que indicam o uso de recursos de sustentabilidade na produção de edificações foram criados, tais como: o norte-americano LEED (Leadership in Energy and Environmental Design) e o francês HQE (Haute Qualité Environnementale). Existem alguns processos de certificação eminentemente nacionais, como a Etiqueta Nacional de Conservação de Energia (ENCE), que enfoca o desempenho energético das edificações avaliadas. Há ainda o Selo Casa Azul CAIXA, que objetiva classificar $O$ desempenho socioambiental de projetos habitacionais financiados pela Caixa Econômica Federal (CEF) (JOHN; PRADO, 2010).

O processo de certificação acontece mediante a concessão de pareceres a edifícios, os quais, dependendo de sua adequação aos critérios e prérequisitos definidos nesses sistemas, podem alcançar a condição de redutores de impactos ambientais (SANTOS; ABASCAL, 2012). Ou seja, considera-se que essas edificações promovem a otimização dos recursos naturais e energéticos aplicados na sua construção e operação.

Embora a participação em um processo de certificação seja voluntária, observa-se que tem crescido a procura pelos selos no Brasil, mesmo em um contexto de crise econômica - sendo que, atualmente, o país lidera o ranking latino-americano de edifícios certificados e ocupa a quarta posição no ranking mundial'. Isso, segundo dados recentes, deve-se à redução dos custos operacionais (de produção e manutenção) dos edifícios certificados e, sobretudo, à expectativa de valorização mercantil dos mesmos. De fato, especialistas demonstram que os selos conseguem melhorar a imagem das empresas promotoras junto aos usuários/investidores, incorporando-se como commodities nas operações de venda, revenda e aluguel dos imóveis (YUDELSON, 2013; KATS, 2014). Afinal, enquanto se estima que o custo de construção, para as edificações certificadas, aumente, em média, entre 0,5\% a $15 \%$, percebe-se valorização de revenda entre $10 \%$ e $20 \%$, além de redução em até $30 \%$ das taxas de condomínio e redução média de $9 \%$ no custo de operação ao longo da vida útil dos edifícios².

Contudo, para além da valorização mercantil dos imóveis, torna-se importante verificar o quanto esses processos realmente contribuem para o desempenho ambiental das edificações brasileiras. Para tanto, a presente pesquisa buscou estudar as três principais metodologias que vêm sendo aplicadas no país: LEED, AQUA (adaptação do HQE) e Casa AzUl (BUENO; ROSSIGNOLO, 2013), sendo que esta comunicação enfoca os selos voltados ao uso residencial.

\section{METODOLOGIA}

\subsection{Identificação dos aspectos gerais dos selos}

Para investigar os processos de certificação, foram comparados os critérios indicados em cada metodologia - os quais, em seu conjunto, são responsáveis por classificarem uma edificação como sustentável (ou não). Com esse intuito,

\footnotetext{
1 Cf. <https://vanzolini.org.br/aqua/indicadores/>. Acesso em: 29 mai. 2019. NUNES, W. Cresce o número de projetos registrados LEED no Brasil em 2018. Disponível em: $<$ http://goinggreen.com.br/2019/03/28/cresce-o-numero-de-projetos-registrados-leed-no-brasilem-2018/>. Acesso em: 29 mai. 2019.

2 Disponível em: <https://construcaomercado.pini.com.br/2017/03/especialistas-apontamrazoes-para-o-crescimento-dos-selos-verdes-na-construcao/>. Acesso em: 29 mai. 2019.
} 
inicialmente, elaboramos um quadro comparativo contrastando as características gerais dos processos destinados ao uso residencial (Figura 1).

\begin{tabular}{|c|c|c|c|}
\hline Selo & GBC CASA (LEED) & AQUA (AQUA-HQE) & CASA AZUL (CAIXA) \\
\hline Ano & 2012 & Versão 2016 & 2010 \\
\hline Estrutura & Checklist & Desempenho & Checklist \\
\hline Restrição & - & - & Financiamento CEF \\
\hline Nível classificação & $\begin{array}{c}\text { Verde (40 a } 49 \text { pontos) } \\
\text { Prata ( } 50 \text { a } 59 \text { pontos) } \\
\text { Ouro ( } 60 \text { a } 79 \text { pontos) } \\
\text { Platina ( } 80 \text { a } 110 \text { pontos) }\end{array}$ & $\begin{array}{l}\text { HQE Pass ( } 4 \text { estrelas + base) } \\
\text { Good ( } 5 \text { a } 8 \text { estrelas) } \\
\text { Very Good ( } 9 \text { a } 12 \text { estrelas) } \\
\text { Excellent ( } 13 \text { a } 15 \text { estrelas) } \\
\text { Exceptional ( } 16 \text { ou mais) }\end{array}$ & $\begin{array}{l}\text { Bronze (critérios obrigatórios- } \\
\text { 19) } \\
\text { Prata (obrigatórios }+6-25 \text { ) } \\
\text { Ouro (obrigatórios }+12-31 \text { ) }\end{array}$ \\
\hline $\begin{array}{l}\text { Número total de } \\
\text { créditos }\end{array}$ & $\begin{array}{l}65 \\
\text { Nem todos são sempre aplicáveis } \\
\text { (ex: regionais são específicos). }\end{array}$ & $\begin{array}{l}58 \\
\text { Menor número que LEED, mas } \\
\text { detalhamento e nível exigência por } \\
\text { critério geralmente maiores. }\end{array}$ & $\begin{array}{l}53 \\
\text { Nem todos são sempre } \\
\text { aplicáveis (ex: reabilitação de } \\
\text { imóveis é específico). }\end{array}$ \\
\hline $\begin{array}{l}\text { Número de pré- } \\
\text { requisitos }\end{array}$ & 14 & $\begin{array}{l}\text { Em quase todos os itens, há nível } \\
\text { base que deve ser atingido. } \\
\text { Portanto, desempenho por critério/ } \\
\text { categoria. }\end{array}$ & 19 \\
\hline Categorias & $\begin{array}{l}\text { 1. Implantação (IMP) } \\
\text { 2. Uso racional da água (URA) } \\
\text { 3. Energia e atmosfera (EA) } \\
\text { 4. Materiais e recursos (MR) } \\
\text { 5. Qualidade ambiental interna } \\
\text { (QAI) } \\
\text { 6. Requisitos sociais (RS) } \\
\text { 7. Inovação e projeto (IP) } \\
\text { 8. Créditos Regionais (CR) }\end{array}$ & $\begin{array}{l}\text { 1. Edifício e seu entorno } \\
\text { 2. Produtos, sistemas e processos } \\
\text { construtivos } \\
\text { 3. Canteiro de obras } \\
\text { 4. Energia } \\
\text { 5. Água } \\
\text { 6. Resíduos } \\
\text { 7. Manutenção } \\
\text { 8. Conforto higrotérmico } \\
\text { 9. Conforto acústico } \\
\text { 10. Conforto visual } \\
\text { 11. Conforto olfativo } \\
\text { 12. Qualidade dos espaços } \\
\text { 13. Qualidade do ar } \\
\text { 14. Qualidade da água }\end{array}$ & $\begin{array}{l}\text { 1. Qualidade Urbana } \\
\text { 2. Projeto e Conforto } \\
\text { 3. Eficiência Energética } \\
\text { 4. Conservação de Recursos } \\
\text { Materiais } \\
\text { 5. Gestão da água } \\
\text { 6. Práticas sociais } \\
\text { 7. Critério Bônus }\end{array}$ \\
\hline
\end{tabular}

Figura 1 - Características gerais dos selos

Fonte: Autores (2019)

O sistema LEED foi desenvolvido pela organização não-governamental norteamericana U.S. Green Building Council (USGBC) a partir de 1993, entrando em vigor em 1998. Há um certificado exclusivo para edificações residenciais, atualizado em 2012 e chamado de GBC Casa (dividido, por sua vez, em Unifamiliar, Condomínios Horizontais e Condomínios Verticais). Os projetos de edificações que pretendem obter essa certificação são analisados a partir de uma lista de verificação (checklist) e segundo 8 categorias, as quais possuem pré-requisitos (itens obrigatórios) e créditos (recomendações que conferem maior pontuação às edificações, caso atendidos). O nível de certificação atingido depende da quantidade de pontos adquiridos: Certificado (40 a 49 pontos), Prata (50 a 59 pontos), Ouro (60 a 79 pontos) ou Platina (80 a 110 pontos). Para a avaliação, além da análise da correspondência entre projeto e documentos que atestam o cumprimento dos requisitos, são realizadas duas vistorias in loco, sendo que todas as etapas da obra devem ser fotografadas e registradas pela equipe de projeto ${ }^{3}$.

\footnotetext{
3 Dados sobre o LEED disponíveis em: <http://gbcbrasil.org.br/sobre-certificado.php>. Acesso em: 10 abr. 2019.
} 
Já o processo AQUA foi desenvolvido a partir da certificação francesa HQE de 1996 e tem sido aplicado no Brasil exclusivamente pela Fundação Vanzolini desde 2008. Essa metodologia fundamenta-se em dois diferentes instrumentos: Sistema de Gestão do Empreendimento (SGE) e Qualidade Ambiental do Edifício (QAE). O primeiro traz as recomendações necessárias para viabilizar o planejamento, a operacionalização e o controle de cada etapa de produção dos empreendimentos, visando ao atendimento do perfil de QAE - responsável por definir as metas de desempenho ambiental. A avaliação da QAE se dá por meio da análise de cada uma das 14 categorias do selo, classificando o desempenho dos edifícios por categoria nos níveis "base", "boas práticas" ou "melhores práticas". A obtenção do selo depende do alcance mínimo de um perfil de desempenho com 3 categorias no nível "melhores práticas", 4 categorias no nível "boas práticas" e, no máximo, 7 categorias no nível "base". Além disso, o desempenho alcançado em cada categoria é relacionado a "estrelas" (por exemplo, um desempenho de nível "base" na categoria "Energia" gera uma estrela), as quais, através da aplicação de fórmulas específicas, levam à classificação do desempenho final do edifício. Após as auditorias, se atendidos os critérios dos referenciais técnicos da certificação e comprovado o alcance do perfil mínimo, o empreendimento é certificado4.

O selo Casa Azul CAIXA, por sua vez, constitui um instrumento de classificação socioambiental de projetos de empreendimentos habitacionais apresentados à Caixa Econômica Federal (CEF) para financiamento ou programas de repasse. Assim, se faz necessário cumprir as determinações do programa ou da faixa de financiamento em que o empreendimento se insere. Como nos demais processos, a verificação do cumprimento dos requisitos é feita por meio de vistorias. Tal qual a certificação LEED, apresenta estrutura de checklist, contendo itens obrigatórios e critérios de livre escolha para cada uma das 6 categorias do selo. Os níveis de classificação dependem da pontuação final obtida (entre 19 e 53 pontos): Bronze (cumprimento dos critérios obrigatórios 19 pontos), Prata (obrigatórios +6 de livre escolha -25 a 30 pontos) e Ouro (obrigatórios +12 de livre escolha -31 pontos ou mais) (JOHN; PRADO, 2010).

\subsection{Comparação entre as categorias dos selos}

As categorias presentes em cada um dos processos também foram relacionadas entre si, de maneira a identificar as semelhanças $e$ as divergências entre essas três metodologias (Figura 2).

\footnotetext{
${ }^{4}$ As informações sobre o selo AQUA foram obtidas em: <https://vanzolini.org.br/aqua/>. Acesso em: 10 abr. 2019.
} 
REFERENCIAL GBC CASA (LEED)

1. Implantação (IMP)

Abrange critérios relacionados à escolha do terreno (infraestrutura, equipamentos e transporte) e itens

relacionados à gestão de água, organização do canteiro e paisagismo.
AQUA

1. Qualidade Urbana

Abrange critérios relacionados à escolha do terreno (infraestrutura,

\section{Implantação}

Gerenciamento das águas pluviais.

2. Uso racional da água

Uso racional (dispositivos economizadores, água não potável) e medição.

\section{Energia e atmosfera}

Desempenho da envoltória; aquecimento de água; iluminação artificial; fontes renováveis; eficiência de equipamentos eletroeletrônicos; medição e comissionamento.

\section{Qualidade ambiental interna}

Gases de combustão; exaustão; controle de umidade; controle de contaminantes; proteção ao radônio (radioatividade); conforto ambiental; acústica.

\section{Materiais e recursos}

Madeira legalizada/ certificada; materiais menor impacto/ certificados; controle de contaminantes; gestão RCD; desmontabilidade

Não há categoria específica. Aparece em Implantação, Materiais e Recursos, Requisitos Sociais.

Não há categoria específica. Aparece em Materiais e Recursos, Requisitos Sociais.

Não há categoria específica. Aparece em Materiais e Recursos, Requisitos Sociais.

\section{Requisitos sociais}

Legalidade e qualidade; acessibilidade; práticas para projeto e obra; práticas para operaçãoe manutenção.

\section{Inovação e projeto}

\section{Créditos regionais}

Maior flexibilidade, ao garantir atendimento itens não previstos. Definição de prioridades regionais. equipamentos e transporte) eà melhoria do entorno.

2. Projeto e Conforto

Há itens da Categoria 2 que dizem respeito à implantação e relação com entorno, como adequação às condições do terreno.
1. Edifício e seu entorno Abrange critérios relacionados à análise do local do terreno, relação com vizinhança e transporte (ecomobilidade).

\section{Gestão da Água}

Uso racional (dispositivos medição; gerenciamento das águas servidas e pluviais. economizadores, água não potável) e
Uso racional (dispositivos economizadores, água não potável) e medição; gerenciamento das águas pluviais; áreas permeáveis.

\section{Energia}

Concepção térmica; aquecimento de água; fontes solares; iluminação artificial; elevadores; eficiência de

\section{Eficiência Energética}

Lâmpadas e dispositivos economizadores; aquecimento de água; elevadores; eficiência de equipamentos; fontes renováveis.

\section{Conforto higrotérmico \\ 9. Conforto acústico \\ 10. Conforto visual \\ 11. Conforto olfativo}

12. Qualidade dos espaços

13. Qualidade do ar

14. Qualidade da água

Itens detalhados por categoria.

\section{Produtos, sistemas e processos} construtivos

Qualidade técnica, ambientale sanitária dos materiais; revestimentos de pisos; fabricantes e fornecedores formais.

\section{Canteiro de obras}

Organização do canteiro; Gestão RCD; Aspectos sociais.

\section{Resíduos}

Gestão dos resíduos (uso e operação): triagem, armazenamento e remoção.

\section{Manutenção}

Água, resíduos, equipamentos.

Legalidade e formalidade; questões sociais sem categoria definida: aparecem como créditos em outras categorias.

\section{Projeto e conforto}

Desempenho térmico; iluminaçãoe ventilação natural.
4. Conservação de Recursos Materiais Qualidade dos materiais; coordenação modular, pré-fabricação/

industrialização; gestão RCD; madeira certificada; Concretos especiais.

Não há categoria específica. Aparece parte em Práticas Sociais e parte em Conservação de Recursos Materiais. Não há categoria específica. Aparece em Práticas Sociais e Conservação de Recursos Materiais.

Não há categoria específica. Aparece em Práticas Sociais e Conservação de Recursos Materiais.

\section{Práticas sociais}

Diferentes iniciativas que abrangem trabalhadores, moradorese comunidade do entorno.

\section{Critério bônus}

Maior flexibilidade, ao garantir atendimento itens não previstos. equipamentos; controle consumo. 


\subsection{Reagrupamento das categorias dos selos}

(i) Implantação/ Relação com entorno

Abrange critérios que buscam orientar a escolha do local de implantação do empreendimento em termos de infraestruturas e equipamentos urbanos existentes, bem como analisar as potencialidades e fragilidades do entorno. A relação com a vizinhança, visando reduzir os incômodos do empreendimento durante sua construção e a manter ou aprimorar as condições de conforto originais, também é contemplada.

(ii) Materiais, produtos e processos construtivos

Categoria que abrange critérios relacionados à escolha dos materiais e sistemas construtivos, com o intuito de reduzir os impactos do setor. Assim, são incentivados produtos e materiais legalizados, certificados, com qualidade técnica adequada à sua função e cujos impactos de seu ciclo de vida sejam conhecidos. Há critérios específicos sobre emprego de madeira e tipos especiais de cimento. Também aborda estratégias relacionadas à redução de entulhos por meio da adoção de processos e sistemas construtivos racionalizados/desmontáveis.

(iii) Canteiro de obras/ Gestão RCD

Trata da organização do canteiro, tendo em vista a preservação da biodiversidade existente, a redução dos impactos ambientais ao longo da construção do empreendimento e a minimização dos incômodos junto à vizinhança (em termos de ruídos e poeira, por exemplo). Foca também critérios relacionados à correta gestão dos resíduos de construção e demolição (RCD) produzidos, visando atender às resoluções do Conselho Nacional do Meio Ambiente (CONAMA) sobre coleta, triagem, disposição e beneficiamento de tais resíduos.

\section{(iv) Energia/ Eficiência energética}

Traz critérios voltados a quantificar e reduzir o consumo de energia elétrica, por meio da melhoria do desempenho térmico da envoltória (com a adoção de níveis adequados de transmitância térmica, estratégias bioclimáticas e orientação adequada ao sol e aos ventos), do uso de sistemas eficientes para o aquecimento de água, do emprego de fontes renováveis, da melhoria da eficiência energética dos sistemas de iluminação artificial e dos demais sistemas/ equipamentos do empreendimento (tais como elevadores, motores e eletrodomésticos). As determinações dessa categoria reverberam normativas nacionais, especialmente a NBR 15220/2003 e o RTQ-R/ Procel Edifica.

\section{(v) Gestão das águas/ Paisagismo}

As recomendações dessa categoria buscam monitorar (medir) e otimizar o consumo de água potável, mediante emprego de dispositivos economizadores e do uso de água não potável. No segundo caso, surgem diretrizes relacionadas à gestão das águas pluviais (com o intuito de também manter e/ou aprimorar as condições originais de escoamento e infiltração dos sítios) e das águas servidas (ainda incipiente nos processos). As estratégias relacionadas à correta escolha de espécies vegetais (paisagismo) por sua adaptação aos climas (reduzindo a necessidade de irrigação) foram situadas nessa categoria.

(vi) Manutenção/ Gestão dos resíduos (uso e operação)

Os critérios abordam a necessidade de informação e divulgação aos moradores/ usuários sobre os sistemas, equipamentos e estratégias ambientais adotadas. Também contempla estratégias que objetivam facilitar as operações de manutenção, especialmente das áreas de armazenamento de resíduos e dos demais sistemas e equipamentos instalados. Trata ainda do gerenciamento dos resíduos de uso e operação do empreendimento, enfatizando a coleta seletiva dos mesmos.

\section{(vii) Conforto ambiental}

Categoria que visa à manutenção de condições adequadas de conforto da edificação em suas diferentes vertentes - conforto higrotérmico (desempenho em relação à existência de variadas condições climáticas ao longo do ano), visual (garantindo-se níveis adequados de iluminação, sobretudo natural, e considerando o contexto visual externo), olfativo (identificando e reduzindo os impactos de fontes de odores) e acústico (ainda incipiente nos processos, com exceção do AQUA). Percebe-se que os critérios são baseados em normativas brasileiras, tais como NBR 15220/2003 e NBR 15575/2013.

\section{(viii) Qualidade ambiental interna}

Abrange tanto a qualidade sanitária dos materiais e componentes da edificação (visando ao controle de contaminantes), quanto dos espaços (com a identificação das fontes internas e externas de poluição, apontando estratégias de ventilação/ exaustão nos ambientes críticos). A qualidade da água faz parte dessa categoria, porém, apenas no processo AQUA é mais abrangente. Nos selos, também são vistos como critérios relacionados à qualidade ambiental interna os itens relativos à acessibilidade dos espaços, à disposição dos equipamentos domésticos e à segurança (contra incêndios e em relação ao patrimôniofísico).

\section{(ix) Práticas sociais/Educação ambiental}

Busca atender à dimensão social da sustentabilidade, por meio de medidas voltadas a diferentes agentes - trabalhadores (educação ambiental, desenvolvimento pessoal e capacitação profissional), moradores (educação ambiental e gestão para manutenção do empreendimento) e comunidade do entorno (participação no processo de projeto, mitigação de riscos sociais e geração de emprego e renda). CASA AZUL como selo que contempla o maior número de estratégias nessa categoria. Ademais, os processos de certificação (com exceção do CASA AZUL) abordam a legalidade/ formalidade das empresas contratadas (construtoras, subcontratadas e prestadores de serviço em geral).

(x) Flexibilidade do selo

Engloba a possibilidade de pontuar soluções não previstas nos selos (ora entendidas como inovação, ora como bônus) - por isso, caráter "flexível" da categoria. No caso do LEED, pontuam-se também os critérios definidos como prioridades regionais em função do local de implantação do empreendimento.

Figura 3 - Reagrupamento das categorias dos selos Fonte: Autores (2019) 
Em seguida, reagrupamos os créditos de cada processo, conforme a correspondência inicialmente estabelecida, nas categorias (Figura 3): (i) implantação/ relação com entorno; (ii) materiais, produtos e processos construtivos; (iii) canteiro de obras/ gestão RCD; (iv) energia/ eficiência energética; (v) gestão das águas/ paisagismo; (vi) manutenção/ gestão dos resíduos (uso e operação); (vii) conforto ambiental; (viii) qualidade ambiental interna; (ix) práticas sociais/ educação ambiental; (x) flexibilidade do selo.

\subsection{Comparação entre os critérios dos selos}

A partir do reagrupamento proposto, foi possível comparar cada critério (obrigatórios ou de livre escolha) dos processos de certificação, como pode ser observado na Figura 4, que traz um exemplo de como foi empreendida tal comparação. No caso ilustrado, contrastamos os critérios relativos ao uso de madeira. As análises pontuais então realizadas permitiram tecer observações gerais sobre os selos.

\begin{tabular}{|c|c|c|}
\hline \multicolumn{3}{|c|}{ MATERIAIS/PRODUTOS/PROCESSOS CONSTRUTIVOS } \\
\hline LEED & AQUA & CASAAZUL \\
\hline $\begin{array}{l}\text { MR Pré-requisito 2: Madeira Legalizada } \\
\text { Uso } 100 \% \text { madeira legalizada, com } \\
\text { comprovação por Documento de } \\
\text { Origem Florestal (DOF) } \\
\text { MR 4.2: Madeira Certificada } \\
\text { Pontuação conforme proporção: } 70 \% \\
\text { uso de madeira certificada (1 ponto); } \\
90 \% \text { uso de madeira certificada (2 } \\
\text { pontos). } \\
\text { Pontuação extra (1 ponto): } 100 \% \\
\text { madeira certificada } \\
\text { Análise: Todos os processos com } \\
\text { determinaçães parecidas a respeito da } \\
\text { madeira (mudança quanto à proporção } \\
\text { de uso de madeira certificadax } \\
\text { pontuação). DOF exigido como pré- } \\
\text { requisito em todos os selos. Portanto, } \\
\text { processos coerentes com realidade } \\
\text { brasileira, em que principal causa de } \\
\text { liberação de CO }{ }_{2} \text { é desmatamento. }\end{array}$ & $\begin{array}{l}2.2 \text { Qualidade ambiental dos materiais, } \\
\text { produtos e equipamentos utilizados } \\
\text { Base: apresentação DOF para madeiras } \\
\text { nativas. } \\
1 \text { ponto: uso madeira de } \\
\text { reflorestamento para estrutura portante } \\
\text { horizontal e vertical, esquadriase } \\
\text { revestimentos. } \\
2 \text { pontos: uso de madeira certificada } \\
\text { para famílias acima. } \\
3 \text { pontos: uso de madeira de } \\
\text { reflorestamento em } 100 \% \text { dos produtos } \\
\text { do edifício e canteiro de obras. } \\
5 \text { pontos: uso de madeira certificada em } \\
100 \% \text { dos produtos do edifício e canteiro } \\
\text { de obras. }\end{array}$ & $\begin{array}{l}\text { 4.9 Madeira plantada ou certificada } \\
\text { Compromisso de uso de madeira } \\
\text { plantada de espécies exóticas ou } \\
\text { madeira certificada. } \\
\text { Memorial descritivo especificando o uso } \\
\text { de madeira de espécies exóticas - que } \\
\text { são necessariamente plantadas -, como } \\
\text { o eucalipto, o pínus, a teca ou de } \\
\text { madeiras certificadas pelo FSC ou } \\
\text { Cerflor, em todas as etapas da } \\
\text { construção e apresentando as } \\
\text { quantidades estimadas. } \\
\text { Apresentação da documentação comprobatória } \\
\text { da aquisição demadeiracertificada e/ou notas } \\
\text { fiscais deaquisição demadeira exótica ao final da } \\
\text { obra. } \\
\text { A apresentação do DOF, não se aplica a } \\
\text { este critério, pois o documento já é } \\
\text { obrigatório para todos os projetos } \\
\text { candidatos ao Selo, sendo, portanto, um } \\
\text { pré-requisito no caso do uso de } \\
\text { madeiras nativas. }\end{array}$ \\
\hline
\end{tabular}

Figura 4 - Comparação entre critérios dos selos, parte do quadro comparativo Fonte: Autores (2019)

\section{RESULTADOS E DISCUSSÃO}

Inicialmente, percebemos que todos os processos se mostraram incompletos quando confrontados uns com os outros - induzindo a conclusão de que, eventualmente, também sejam insuficientes para uma devida classificação de edificações em termos de sustentabilidade. Considerando apenas a categoria "Implantação", por exemplo, O LEED não analisa os impactos do empreendimento no entorno (no que tange à relação com a vizinhança, em termos de incômodos causados pela construção dos empreendimentos). Por outro lado, o processo AQUA não define restrições quanto à presença de infraestrutura básica para a implantação das edificações (ainda que a definição do local de implantação deva considerar as características urbanas 
do entorno). Já o selo Casa Azul é pouco restritivo quanto à provisão de condições adequadas de insolação à vizinhança. Por outro lado, há critérios bastante específicos e pontuais em todos os selos (cuja pertinência pode ser questionada). Como exemplos, podem ser citados os critérios controle da umidade local $^{5}$ (LEED) e pavimentação com resíduos de construção e demolição (RCD) ${ }^{6}$ (CASA AZUL).

Também foram identificadas fragilidades em cada selo. No caso do LEED, percebeu-se que o processo se concentra mais em avaliar o desempenho da própria edificação, dando pouca atenção aos impactos causados à vizinhança. Além disso, faltam recomendações, presentes nos outros métodos, sobre: uso de modais de transporte alternativos; qualidade técnica dos materiais/ componentes (segundo o Programa Brasileiro de Produtividade e

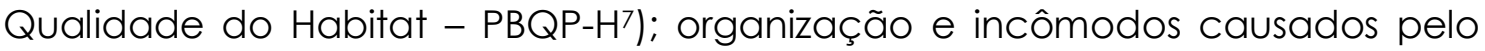
canteiro; iluminação natural; conforto olfativo e qualidade da água (para além do monitoramento da água não potável). No entanto, o processo apresenta critérios exclusivos e pertinentes que poderiam ser incorporados por outros selos (como redução de ilha de calor e gerenciamento da qualidade, visando à durabilidade).

Quanto ao AQUA, a categoria "Práticas sociais/ Educação ambiental" é pouco considerada, visto que não trata de questões relacionadas à educação, ao desenvolvimento e à capacitação da mão-de-obra e dos usuários como os outros selos. A abordagem social desse processo limita-se à garantia da formalidade dos prestadores de serviços/ construtoras/ subcontratadas e ao cumprimento dos direitos trabalhistas. Também não há a categoria de "Flexibilidade do selo" para permitir o emprego de soluções não previstas inicialmente nos projetos. Além do mais, faltam recomendações, presentes nos outros processos, sobre: presença de infraestrutura básica para implantação dos empreendimentos; estratégias construtivas racionalizadas/ desmontáveis visando à redução de entulhos; e paisagismo. Contudo, esse é o processo mais abrangente e exigente com relação às categorias "Conforto ambiental", "Qualidade ambiental interna" e "Manutenção/ Gestão de resíduos (uso e operação)".

Sobre o Casa Azul - embora, de maneira geral, perpasse todas as categorias de análise -, as exigências são ainda pouco restritivas. Destaca-se a categoria "Práticas sociais/ Educação ambiental", a qual assume maior protagonismo que as demais voltadas à análise do desempenho ambiental da edificação. Faltam recomendações, encontradas nos outros métodos, sobre: materiais

\footnotetext{
${ }^{5}$ Define a manutenção da taxa de umidade relativa entre 40 e $60 \%$ para alguns locais (como quartos). Dada a diversidade de climas no Brasil, manter os padrões de umidade indicados, muito provavelmente, requer a dependência de sistemas e equipamentos ativos - o que nem sempre pode ser viável ou desejável (também do ponto de vista do consumo energético).

6 Pontua especificamente o projeto de pavimento que faz uso de agregados derivados da reciclagem de RCD, porém, não traz recomendações acerca do beneficiamento e emprego de RCD no próprio setor (para além do seu uso como pavimentação).

7 O Programa Brasileiro de Produtividade e Qualidade do Habitat (PBQP-H) tem o intuito de organizar o setor da construção civil visando à melhoria da qualidade do habitat e à modernização produtiva. Para tanto, desenvolve ações como, entre outras: avaliação da conformidade de empresas de serviços e obras, melhoria da qualidade de materiais, normalização técnica e avaliação de tecnologias inovadoras. Cf.: <http://pbqph.cidades.gov.br/pbqp_apresentacao.php>. Acesso em: 01 jun. 2019.
} 
certificados, com fichas de informação do produto8; beneficiamento e reuso de RCD; organização e incômodos causados pelo canteiro; reuso e gestão das águas servidas; iluminação natural (para além das áreas comuns e de banheiros); conforto acústico; qualidade sanitária dos materiais e produtos; qualidade do ar e da água (para além do monitoramento da água não potável); e formalidade das empresas contratadas.

É possível apontar ainda aspectos pouco desenvolvidos em todas as metodologias analisadas. Por exemplo, há recomendações detalhadas no que tange à gestão e reuso das águas pluviais, mas não das águas servidas. Em relação ao conforto lumínico, o processo LEED não trata de iluminação natural, enquanto o Casa Azul aborda apenas a iluminação natural de áreas comuns e de banheiros. Por outro lado, embora o AQUA seja mais abrangente nesse quesito, assim como os outros selos, não enfoca o conforto lumínico relacionado aos sistemas de iluminação artificial'?.

Ainda que $O$ LEED, de maneira mais sucinta, e O AQUA, de maneira mais abrangente, tratem da acústica dos espaços, percebe-se que essa vertente da categoria "Conforto Ambiental" também é pouco aprofundada em todos os processos. Tendo em vista o índice de desconforto acústico experimentado nas unidades residenciais brasileiras (FRANÇA; NIEMEYER; SANTOS, 2011; VILLA; SARAMAGO; GARCIA, 2015), reforça-se a necessidade de que o desempenho acústico das edificações seja melhor avaliado.

A existência de critérios quanto ao uso de modais alternativos é incipiente nos três sistemas de acreditação. As estratégias, quando existentes, são pontuais e pouco relacionadas com o contexto de inserção dos empreendimentos. Levando em consideração a significativa parcela de contribuição ao aquecimento global pelo setor de transportes (AGOPYAN; JOHN, 2011), inferese que seria importante a previsão de recomendações mais aprofundadas em relação a esse critério de desempenho ambiental. Por fim, a questão da organização/ distribuição espacial não aparece nos selos: veja-se, por exemplo, o fato de que os processos abordam a qualidade dos espaços predominantemente do ponto de vista da acessibilidade. Em recente dissertação, Figueiredo (2018) apontou justamente essa fragilidade.

Para além das críticas relacionadas à comparação entre os critérios de cada selo aqui apresentada, recorreu-se a trabalhos anteriores que analisaram processos de certificação de edificações, de maneira a verificar se os aspectos previamente compreendidos enquanto falhas foram superados nas correntes versões dos métodos ou se os problemas continuam a existir. Nesse sentido, uma questão correntemente indicada na literatura referia-se ao fato de que metodologias baseadas em listas de verificação (checklists), visando simplificar o processo avaliativo para facilitar sua aplicação prática pelos agentes de construção, não garantiam um bom desempenho global das edificações. Isso porque nem todos os critérios precisavam ser cumpridos e inexistia ponderação dos pontos. Assim, de acordo com os textos consultados

\footnotetext{
8 As fichas de informação do produto são usadas para indicar os impactos relativos a determinado material/ componente construtivo, incluindo as etapas de extração, beneficiamento e transporte.

9 Conceitos luminotécnicos como ofuscamento, IRC (Índice de Reprodução de Cores), TCC (Temperatura de Cor) e nível de iluminação não são analisados - a iluminação artificial, nos processos, aparece relacionada apenas com eficiência energética.
} 
(SILVA; SILVA; AGOPYAN, 2003; PATRÍCIO; GOUVINHAS, 2004; COSTA; MORAES, 2013), o preenchimento dessa coleção de estratégias orientadas a dispositivos diminuía a complexidade dos processos de avaliação: poderia levar a alguma melhoria de desempenho, mas não necessariamente assegurava edifícios de melhor desempenho geral.

Pelas análises efetuadas, essa crítica ainda é válida para os processos LEED e Casa AzUl. No caso do AQUA, por sua vez, toda a avaliação baseia-se em desempenho (por categoria e global). Já para o LEED e Casa Azul, apenas o cumprimento dos pré-requisitos não implica em desempenho adequado em todas as categorias. Além disso, a classificação final desses métodos é dada por somatória de pontos. Portanto, por exemplo, é possível ter desempenho exemplar em uma categoria e cumprir apenas critérios obrigatórios em outra.

A relevância da categoria "Práticas sociais/ Educação ambiental", acima apontada, visa responder, por outro lado, à questão inicialmente levantada por Silva, Silva e Agopyan (2003) sobre a necessidade de que os sistemas de avaliação de edifícios então praticados incorporassem as dimensões social e econômica da sustentabilidade, tratando não apenas da avaliação do desempenho ambiental das edificações. Conforme visto, tanto o Casa Azul quanto O LEED (o qual, a partir de 2012, replicou os requisitos definidos inicialmente pelo selo da CEF) incorporaram critérios relativos à sustentabilidade social dos empreendimentos residenciais brasileiros, de maneira que O AQUA continua sendo a única metodologia centrada quase que exclusivamente no desempenho ambiental (como prática social, este processo enfoca o estímulo à formalidade de fabricantes e prestadores de serviço, além do cumprimento de leis trabalhistas). Isso pode ser encarado enquanto uma fragilidade da metodologia em face à realidade do setor construtivo brasileiro, em que ações voltadas à educação ambiental de trabalhadores e usuários das edificações deveriam ser incentivadas para se reduzir os impactos do ambiente construído, especialmente na produção habitacional (SARAMAGO et al., 2014; VILLA; SARAMAGO; GARCIA, 2015).

Silva, Silva e Agopyan (2003), em seu texto, indicavam ainda a importância de que os sistemas existentes se aproximassem de análises do ciclo de vida $(\mathrm{ACV})^{10}$. Mesmo entendendo a dificuldade de tal fundamentação, os autores insistiam na necessidade de se promover a identificação e a criação de bases de dados ambientais sobre materiais e produtos construtivos, produzidos e comercializados no país, empregando-se essas informações na avaliação global dos edifícios.

Analisando-se as metodologias atualmente praticadas, é possível dizer que esse aspecto ainda é deficiente no Casa Azul, mas aparece com maior abrangência no LEED e no AQUA. De maneira geral, percebe-se que o setor de construção brasileiro pouco evoluiu no que concerne à coleta e disponibilização de dados sobre o ciclo de vida de produtos/ componentes construtivos. Assim, mesmo quando os selos valorizam o emprego de materiais certificados, por exemplo, nem sempre a escolha por esses materiais é

10 A Avaliação do Ciclo de Vida (ACV) é embasada em uma abordagem sistêmica, conhecida como "do berço ao túmulo", que considera dados sobre impactos ambientais em todas as fases do ciclo de vida de um produto ou serviço: extração de matérias-primas, produção, distribuição, consumo (uso e manutenção) e disposição final - contemplando reciclagem e reuso, quando for o caso. Para mais, ver: <http://acv.ibict.br/acv/o-que-e-o-acv/>. Acesso em: 10 abr. 2019. 
relacionada ao seu transporte ou à sua disposição final - etapas do ciclo de vida que podem ser mais impactantes em comparação ao seu processo de produção (AGOPYAN; JOHN, 2011), principalmente no caso de itens importados.

Outro cuidado frequentemente salientado na literatura dizia respeito à importação de métodos concebidos para países com condições socioeconômicas, climáticas e culturais diferentes daquelas brasileiras, exigindo-se maior atenção na implementação de tais sistemas de acreditação (SILVA; SILVA; AGOPYAN, 2003; VIEIRA; BARROS FILHO, 2009; BUENO, 2010). No que tange a esse aspecto, percebe-se que houve adaptação dos processos à realidade brasileira, na medida em que passaram a se basear em normativas de desempenho nacionais (especialmente NBR 15220/2003'1, NBR $15575 / 2013^{12}$, RTQ-R ${ }^{13}$ e RTQ-C ${ }^{14}$ ). Sendo assim, as críticas sobre esse item foram respondidas, adequando-se os processos ao contexto de construção do país (especialmente sobre o emprego de sistemas passivos para climatização).

Por fim, importa ponderar que, mesmo utilizando normativas nacionais, algumas exigências e parâmetros dessas próprias regulamentações vêm sendo criticadas por estudiosos da área: o zoneamento bioclimático brasileiro da NBR 15220/2003 não contempla todos os tipos de clima do país (PEREIRA; ASSIS, 2005); certos parâmetros de conforto térmico precisariam ser revistos na NBR 15220/2003 e na NBR 15575/2013, sendo que há incoerências entre as exigências dessas duas normativas (MORAIS; LABAKI, 2015; FERREIRA; SOUZA; ASSIS, 2015); enquanto a metodologia do RTQ-R é considerada muito simplificada (LOURA; ASSIS; BASTOS, 2011). Desse modo, os processos continuam inconsistentes, pois se apoiam em regulamentações que também apresentam fragilidades. Ainda que o aprimoramento dos selos seja contínuo, como já exposto, negligenciar essa realidade, quando da avaliação da viabilidade de sua aplicabilidade, seria imprudente.

\footnotetext{
11 A norma da ABNT NBR 15220/2003, intitulada "Desempenho térmico de edificações", entre outros aspectos, define parâmetros construtivos para habitações brasileiras em função das características climáticas de seu local de inserção (conforme zoneamento bioclimático brasileiro, que definiu 8 regiões climáticas para $\bigcirc$ país). Ver: <https://drive.google.com/file/d/OB IwonbRQVwwgXIF3YWplbUICSkk/view>. Acesso em: 30 mai. 2019.

12 A NBR 15575/2013 trata do desempenho de edificações habitacionais até cinco pavimentos, indicando requisitos sobre: desempenho do sistema estrutural; segurança contra incêndio; segurança no uso e na operação; estanqueidade; desempenho térmico; desempenho acústico; desempenho luminoso; durabilidade e manutenibilidade; saúde, higiene e qualidade do ar; funcionalidade e acessibilidade; conforto tátil e antropodinâmico; e adequação ambiental. Ver: $<$ http://www.caubr.gov.br/wpcontent/uploads/2015/09/2_guia_normas_final.pdf>. Acesso em: 30 mai. 2019.

13 Regulamento Técnico da Qualidade para o Nível de Eficiência Energética de Edificações Residenciais, instrumento que define os requisitos técnicos para a avaliação de habitações dentro do Programa Brasileiro de Etiquetagem (PBE). Disponível em: $<$ http://www.pbeedifica.com.br/sites/default/files/projetos/etiquetagem/residencial/downloads/ RTQR.pdf>. Acesso em: 30 mai. 2019.

14 Regulamento Técnico da Qualidade para o Nível de Eficiência Energética de Edificações Comerciais, de Serviços e Públicas, instrumento que define os requisitos técnicos para a avaliação dessas tipologias dentro do PBE. Disponível em: $<$ http://www.pbeedifica.com.br/sites/default/files/projetos/etiquetagem/comercial/downloads/ Port372-2010_RTQ_Def_Edificacoes-C_rev01.pdf>. Acesso em: 30 mai. 2019.
} 


\section{CONSIDERAÇÕES}

Esta pesquisa reconhece o importante papel do estabelecimento de parâmetros mínimos de desempenho das edificações para superar as patologias que as acompanham. No entanto, insiste na insuficiência dos critérios de avaliação de sustentabilidade até o momento exigidos: pela análise proposta, concluímos que, se inexiste um patamar mínimo de concordância quanto aos critérios que autorizam sistemas de acreditação em sustentabilidade, então também parece não haver concordância quanto ao que seria sustentabilidade na construção civil - particularmente na produção residencial aqui analisada. Na realidade brasileira, propõe-se que sistemas de acreditação se tornem obrigatórios para novas construções e para reformas de edifícios já existentes. Nesse sentido, é imprescindível enfrentarmos a discussão dos parâmetros envolvidos em sua formulação.

\section{REFERÊNCIAS}

BUENO, C. Avaliação de desempenho ambiental de edificações habitacionais: análise comparativa dos sistemas de certificação no contexto brasileiro. 2010. Dissertação (Mestrado) - Escola de Engenharia de São Carlos da Universidade de São Paulo, São Carlos, 2010.

BUENO, C.; ROSSIGNOLO, J. A. Análise dos sistemas de certificação ambiental de edifícios residenciais no contexto brasileiro. Risco, São Carlos, 17, p.6-22, 2013.

COSTA, E. D.; MORAES, C. S. B. Construção civil e a certificação ambiental: análise comparativa das certificações LEED (LEADERSHIP IN ENERGY AND ENVIRONMENTAL DESIGN) e AQUA (ALTA QUALIDADE AMBIENTAL). Engenharia Ambiental, Espírito Santo do Pinhal, v.10, n.3, p.160-169, maio/ jun., 2013.

FERREIRA, C. C.; SOUZA, H. A.; ASSIS, E. A. Comparação de desempenho de envoltórias recomendadas por normas de desempenho e Mahoney. In: XII ENCONTRO NACIONAL E IX ENCONTRO LATINO-AMERICANO DE CONFORTO NO AMBIENTE CONSTRUÍDO, Campinas, 2015. Disponível em: <http://www.infohab.org.br/encac/files/2015/topico4artigo08.pdf>. Acesso em: 07 nov. 2018.

FIGUEIREDO, A. C. C. Certificação ambiental e habitação no Brasil: agentes e requisitos urbanísticos e arquitetônicos. 2018. Dissertação (Mestrado) - Instituto de Arquitetura e Urbanismo, Universidade de São Paulo, São Carlos, 2018.

FRANÇA, P.; NIEMEYER, M. L.; SANTOS, M. Análise de conforto acústico do conjunto habitacional Bento Ribeiro Dantas, e avaliação da interferência do ruído da via expressa linha amarela sobre as habitações. In: XI ENCONTRO NACIONAL E VII ENCONTRO LATIOAMERICANO DE CONFORTO NO AMBIENTE CONSTRUÍDO, 2011, Búzios. p.1-10. Disponível em: <http://www.infohab.org.br/encac/files/2011/topicol artigo03.pdf>. Acesso em: 06 nov. 2018.

JOHN, V. M.; PRADO, R. T. (Coord.) Boas práticas para habitação mais sustentável. São Paulo: Páginas \& Letras, 2010.

KATS, G. Tornando nosso ambiente construído mais sustentável: custos, benefícios e estratégias. São Paulo: Secovi, 2014. 
LOURA, R. M.; ASSIS, E. S.; BASTOS, L. E. G. Análise comparativa entre resultados de desempenho térmico de envoltórias de edifício residencial gerados por diferentes normas brasileiras. In: XI ENCONTRO NACIONAL e VII ENCONTRO LATINOAMERICANO DE CONFORTO NO AMBIENTE CONSTRUÍDO, 2011, BúZIOS.

Anais... Búzios: ANTAC, 2011. Disponível em: <http://www.infohab.org.br/encac/files/2011/Top4art28.pdf >. Acesso em: 07 nov. 2018.

MORAIS, J. C.; LABAKI, L. C. NBR 15220-3: uma reflexão sobre os parâmetros de projeto para ventilação natural. In: XII ENCONTRO NACIONAL e IX ENCONTRO LATINO-AMERICANO DE CONFORTO NO AMBIENTE CONSTRUÍDO, 2015, Campinas. Anais... Campinas: ANTAC, 2015. Disponível em:

<http://www.infohab.org.br/encac/files/2015/topico5artigo23.pdf>. Acesso em: 07 nov. 2018.

PATRíCIO, R. M. R; GOUVINHAS, R. P. Avaliação de desempenho ambiental em edificações: diretrizes para o desenvolvimento de uma nova metodologia adaptada à realidade do Nordeste. In: I CONFERÊNCIA LATINO-AMERICANA DE CONSTRUÇÃO SUSTENTÁVEL E X ENCONTRO NACIONAL DE TECNOLOGIA DO AMBIENTE CONSTRUÍDO, 2004, São Paulo. Anais... São Paulo: ANTAC, 2004.

PEREIRA, I.; ASSIS, E. S. Discussão da classificação bioclimática de Belo Horizonte proposta pelo projeto de norma de desempenho térmico de edificações. In: VIII ENCONTRO NACIONAL e VI ENCONTRO LATINOAMERICANO DE CONFORTO NO AMBIENTE CONSTRUÍDO, 2005, Maceió. Anais... Maceió: ANTAC, 2005. Disponível em: <http://www.infohab.org.br/encac/files/2005/ENCAC05_1490_1498.pdf>. Acesso em: 07 nov. 2018.

SANTOS, M. F.; ABASCAL, E. H. S. Certificação LEED e arquitetura sustentável: edifício Eldorado Business Tower. Arquitextos, ano 12, jan. 2012. Disponível em: <http://www.vitruvius.com.br/revistas/read/arquitextos/12.140/4126>. Acesso em: 04 nov. 2018.

SARAMAGO, R. C. P.; VILLA, S. B.; BEZZON, E. F. A.; CARVALHO, L. A. Qualidade ambiental e sustentabilidade em edifícios de apartamentos de cidades médias. In: Encontro Nacional de Tecnologia do Ambiente Construído, 15. 2014, Maceió. Anais do XV Encontro Nacional de Tecnologia do Ambiente Construído. Maceió: Marketing Aumentado, 2014, p.233-242.

SILVA, V. G.; SILVA, M. G.; AGOPYAN, V. Avaliação de edifícios no Brasil: da avaliação ambiental para avaliação de sustentabilidade. Ambiente Construído, v.3, n.3, p.8-18, 2003.

VIEIRA, L. A.; BARROS FILHO, M. N. M. A emergência do conceito de arquitetura sustentável e os métodos de avaliação do desempenho ambiental de edificações. Humanae, v.1, n.3, p. 1-26, dez. 2009.

VILLA, S. B.; SARAMAGO, R. C. P; GARCIA, L. C. Avaliação pós-ocupação no programa Minha Casa Minha Vida: uma experiência metodológica. Uberlândia: Universidade Federal de Uberlândia; PROEX, 2015

VASCONCELOS, D. L. B.; VASCONCELOS, R. L. Sustentabilidade: ferramenta de marketing ou instrumento essencial. In: VII Seminário Internacional da LARES, 2008, São Paulo. Disponível em: <http://www.lares.org.br/2008/img/Artigo022Batalha-Vasconcelos_Rev_2.pdf>. Acesso em: 06 nov. 2018. 
YUDELSON, J. Projeto integrado e construções sustentáveis. Porto Alegre: Bookman, 2013. 